\title{
The C-D interhelical domain of the serpin plasminogen activator inhibitor-type 2 is required for protection from TNF- $\alpha$ induced apoptosis
}

\author{
Joanne L. Dickinson ${ }^{1,3}$, Belinda J. Norris ${ }^{1}$, Poul H. Jensen ${ }^{2}$ \\ and Toni M. Antalis ${ }^{1,4}$ \\ ${ }^{1}$ Queensland Cancer Fund Experimental Oncology Unit, The Queensland \\ Institute of Medical Research, Brisbane, 4029, Australia \\ 2 Department of Medical Biochemistry, University of Aarhus, Aarhus, Denmark \\ DK-8000 \\ 3 Present address: The Eye Clinic, GPO Box 10616 Royal Hobart Hospital, \\ Tasmania, 7001 Australia \\ ${ }^{4}$ corresponding author: Queensland Institute of Medical Research, Post Office. \\ Royal Brisbane Hospital, Brisbane 4029 Australia. tel: +61 73362 0312; fax: \\ +61 73362 0107; e-mail: toniA@qimr.edu.au
}

Received 10.6.97; revised 11.8.97; accepted 9.9.97

Edited by S. Nagata

\begin{abstract}
The serine proteinase inhibitor (serpin), plasminogen activator inhibitor type 2 (PAI-2), has been reported to inhibit tumor necrosis factor- $\alpha$ (TNF) induced apoptosis. In order to begin to understand the molecular basis for this protection, we have investigated the importance of a structural domain within the PAI-2 molecule, the C-D interhelical region, in mediating the protective effect. The $C$-D interhelical region is a 33 amino acid insertion which is unique among serpins and has been implicated in transglutaminase catalyzed cross-linking of PAI2 to cell membranes. We have constructed a mutant of PAI-2 wherein 23 amino acids are deleted from the C-D interhelical region generating a structure predicted to be homologous to the closely related, but non-inhibitory serpin, chicken ovalbumin. The PAI-2 $\triangle 65 / 87$ deletion mutant retained inhibitory activity against its known serine proteinase target, urokinase-type plasminogen activator (uPA); however expression of this mutant in HeLa cells failed to protect from TNF-induced apoptosis. Analyses of the cellular distribution of PAl-2 showed that intracellular PAI-2, and not secreted or cell-surface PAI-2, was likely responsible for the observed protection from TNF-induced apoptosis. No evidence was found for specific cross-linking of PAl-2 to the plasma membrane in either control or TNF/cycloheximide treated cells. The data demonstrate that the PAI-2 C-D interhelical domain is functionally important in PAI-2 protection from TNF induced apoptosis and suggest a novel function for the C-D interhelical domain in the protective mechanism.
\end{abstract}

Keywords: plasminogen activator inhibitor; tumor necrosis factor; apoptosis; cell death; serpin

Abbreviations: bp, base pairs; kb, kilobase(s); PAl-2, plasminogen activator inhibitor type-2; RSL, reactive site loop; serpin, serine proteinase inhibitor; tumor necrosis factor- $\alpha$, (TNF); urokinase-type plasminogen activator, uPA

\section{Introduction}

Plasminogen activator inhibitor type 2 (PAl-2) is a member of the serine proteinase inhibitor, or serpin, superfamily. Members of the serpin superfamily share a highly ordered tertiary structure defined by the crystal structure of the prototype serpin $\alpha 1$-antitrypsin (Loebermann et al, 1984). $\mathrm{PAl}-2$ is recognised as belonging to a subgroup of serpins designated the ov-serpin (ovalbumin-like) family, defined by several common features such as amino acid sequence homology and gene organization (Remold-O'Donnell, 1993). The specific functions of this diverse sub-family of molecules are only beginning to be elucidated. The best characterised of the ov-serpins, the viral serpin, crmA, is an inhibitor of interleukin-1 $\beta$ converting enzyme (ICE)-like caspases involved in both TNF $\alpha$ and FAS induced apoptosis (Zhou et al, 1997).

PAI-2 has been well characterised as an inhibitor of the extracellular serine proteinase, urokinase-type plasminogen activator (UPA) (Kruithof et al, 1995). uPA catalyses the activation of plasminogen to plasmin, a broad spectrum serine proteinase which plays a central role in fibrinolysis, extracellular matrix degradation and in the activation of cytokines and growth factors in the extracellular milieu (Testa and Quigley, 1990). While PAI-2 can be found as a secreted extracellular form, the majority of PAI-2 synthesized by many cells remains intracellular (Kruithof et al, 1995). Recent studies (Kumar and Baglioni, 1991; Dickinson et al, 1995) demonstrate a novel function for $\mathrm{PAl}-2$ in the regulation of apoptosis induced by the inflammatory cytokine, tumour necrosis factor- $\alpha$ (TNF) and in inhibition of apoptosis mediated by Mycobacterium avian (Gan et al, 1995). PAl-2 mediated resistance to TNF $\alpha$ is not due to the loss of TNF $\alpha$-receptor or to the loss of TNF $\alpha$-receptor binding activity (Dickinson et al, 1995). While the mechanism(s) by which PAI-2 protection occurs is as yet unknown, UPA does not appear to be the target of PAl-2 action (Dickinson et al, 1995) and PAl-2 has not been found to inhibit PAI-2 has not been found to inhibit ICE-like caspases associated with apoptosis (Dickinson et al, 1995; unpublished data).

The amino acid sequence of PAI-2, deduced from cDNA and genomic clones (Ye et al, 1987, 1989; Antalis et al, 1988; Schleuning et al, 1987; Samia et al, 1990) reveals several structural domains which may contribute to PAI-2 function. PAI-2 lacks a cleavable hydrophobic signal sequence, which is believed to account for the existence of both intracellular Mr 46000 and secreted Mr 60-70 000 
forms of PAl-2. By analogy with other members of the serpin superfamily, an exposed reactive site loop (RSL) contains the $\mathrm{P}_{1}-\mathrm{P}_{1}^{\prime}$ amino acid residues and acts as a bait for the target proteinase (Kiso et al, 1988). Mutagenesis studies show that the presence of the $\mathrm{P}_{1}$ - $\mathrm{Arg}^{380}$ amino acid residue of $\mathrm{PAI}-2$ is required for inhibition of TNF-mediated apoptosis as cells expressing PAI-2 with an Ala in this position are sensitive to cytolysis by TNF (Dickinson et al, 1995).

A third feature unique to the ov-serpins is an extended amino acid domain located in the region between $\alpha$-helices $\mathrm{C}$ and $\mathrm{D}$ based on the predicted structural model of PAI-2 (Antalis et al, 1988). This domain is non-homologous among the serpin family, is variable in length, and is unusually long in PAI-2 (33 residues) in comparison with other ovalbumin serpin members. In vitro studies show that glutamines contained within the C-D interhelical region can act as substrates for transglutaminase (Jensen et al, 1994). Recently several cellular proteins have been identified which reversibly bind to this PAI-2 domain, including annexins I and II, as well as several as yet unidentified proteins which associate with PAI-2 following crosslinking and immunoprecipitation (Jensen et al, 1996). However, an in vivo physiological role for this domain has not been demonstrated. In the present study, we have generated cells expressing a PAI-2 mutant lacking the C-D interhelical region and report for the first time an intracellular functional role for this domain in the protection of cells from TNFinduced apoptosis.

\section{Results \\ The C-D interhelical region is highly conserved between species}

Members of the serpin superfamily, including PAI-2, have a highly conserved tertiary structure. Alignment of the amino acid residues of PAI-2 with other members of the serpin superfamily using the crystal structure of $\alpha 1$-antitrypsin as the prototype shows that PAI- 2 contains an unusually long extended sequence located between predicted helices $C$ and $\mathrm{D}$ and spanning amino acids 65-87 (Antalis et al, 1988). Comparison of the amino acid sequences of human, mouse, and rat PAI-2s shows that the amino acids contained within this region are highly conserved between species (Figure 1a).

\section{Generation of mutant PAI-2 lacking the C-D interhelical region}

In order to investigate the importance of the C-D interhelical region for the biological function of PAI-2, a mutant PAI-2 cDNA was engineered in which a 22 amino acid sequence within the C-D interhelical region was deleted (PAI-2 $\Delta 65 / 87$ ) (diagrammed in Figure 1A). The rationale for this mutation was to remove amino acids not present in chicken ovalbumin, a structurally related serpin which has no known protease inhibitor activity. Thus possible secondary structural effects should be minimized. PAI-2 $\Delta 65 / 87$ was inserted into the
$\mathbf{A}$

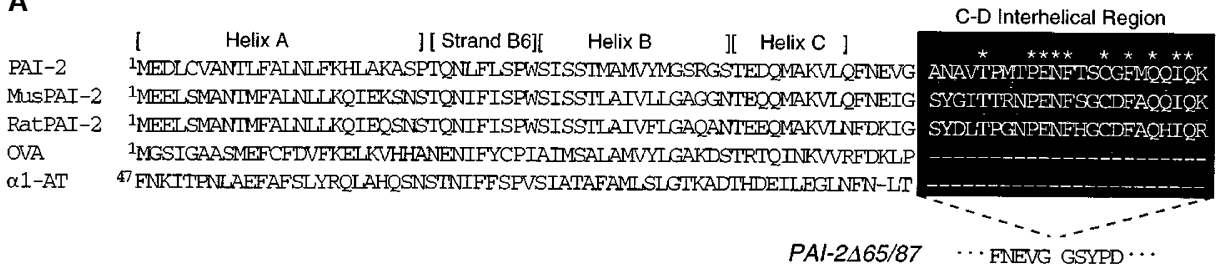

B

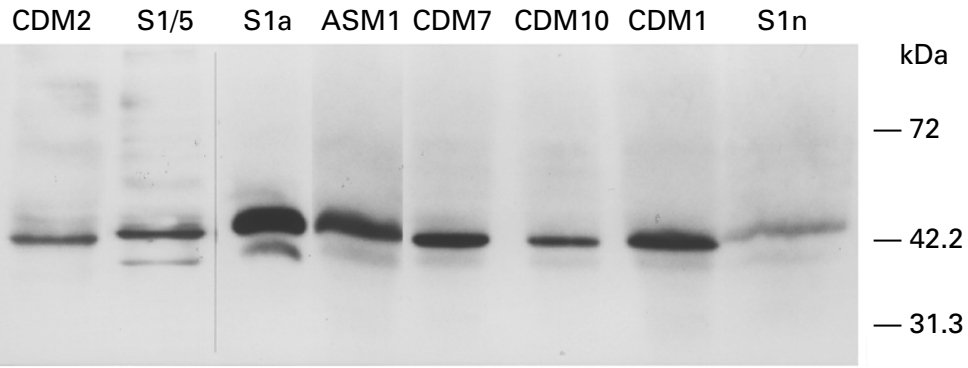

C

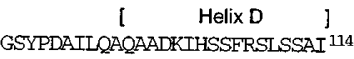
ENYPSAILQAQAGDKIHSAFSSLSSTI 114 DNYPVAILOAOARDKTHSAFSSLSSTI ${ }^{114}$ GFGDSIEAOCGTSVNVHSSLRDINNOI 91 GFGDSIEAQCGTSVMVHSSLRDIINQI 91
Figure 1 (A) The PAI-2 C-D interhelical region. Alignment of the C-D interhelical amino acid sequences derived from the cDNA sequences of PAI-2 from human mouse and rat PAI- 2 relative to the other serpins, chicken ovalbumin and $\alpha 1$-antitrypsin and showing the 22 amino acid deletion within the $\mathrm{C}$-D interhelical region to generate PAI-2 $\Delta 65 / 87$. The amino acid sequences were obtained from entries in the NCBI Genebank Database (Accession Numbers: human, J03603; mouse, X16490; rat, X64563). Conserved amino acids are indicated by asterisks. (B) PAI-2 $265 / 87$ expression in representative CDM transfectants. PAI-2 protein was detected in lysates from representative CDM transfectants following immunoblot anaylsis using anti-PAI-2 monoclonal antibody. CDM2, CDM7, CDM10, and CDM1 express PAI-2 $265 / 87$. S1n, S1/5 and S1a express different levels of wild-type $46 \mathrm{kD}$ PAl-2 and ASM1 expresses Ala ${ }^{380}$-PAl-2. (C) Binding of PAI-2 $\Delta 65 / 87$ to ${ }^{125}$ IUPA. Lane 1, S1/5 cells expressing wild-type PAI-2; Lane 2, CDM2 cells expressing PAI-2 $\Delta 65 / 87$; Lane 3, A2/7 cells expressing anti-sense PAI-2; Lane 4, parental $\mathrm{HeLa}$ cells. The band at $75 \mathrm{kD}$ represents ${ }^{125} \mathrm{I}$-uPA complexed to the PAI-2 species. A $34 \mathrm{kD}{ }^{125} \mathrm{I}$-uPA heavy chain is present in all lanes. The $60 \mathrm{kD}$ band is an unidentified band present in all lanes but not in the tracer (data not shown). The difference in migration due to deletion of the C-D interhelical region is not visible 
A.

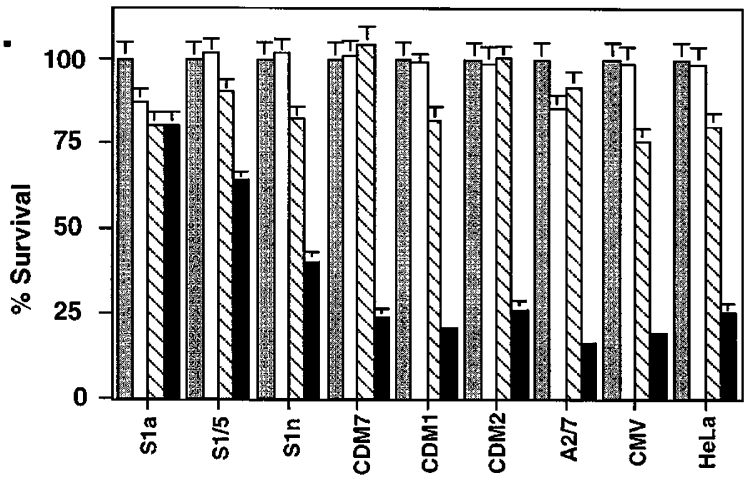

B.

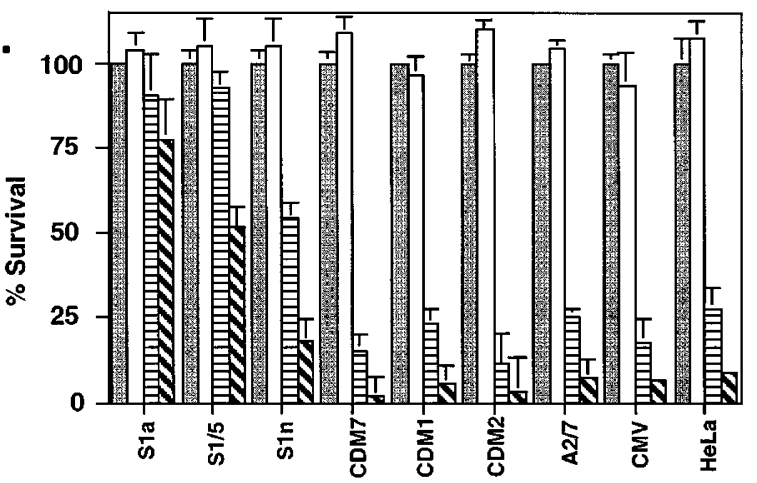

C.

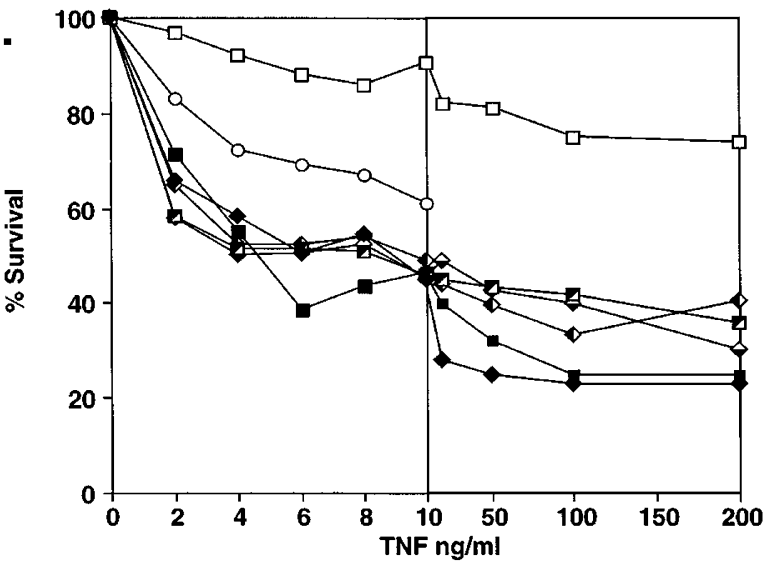

Figure 2 Relative survival of representative PAI-2 clones expressing wildtype and PAI-2 $\Delta 65 / 87$. (A) Cell survival following treatment with TNF and cycloheximide measured by crystal violet assay. The wild-type PAI-2 expressing HeLa transfectants S1a, S1/5 and S1n; PAI-2 $\Delta 65 / 87$ expressing CDM7, CDM2, and CDM1; antisense PAI-2 expressing A2/7; the vector alone transfectant $\mathrm{CMV}$; and parental HeLa cells were assayed untreated ( $\square$ ) or following treatment with $10 \mathrm{ng} / \mathrm{ml}$ TNF $(\square), 10 \mu \mathrm{g} / \mathrm{ml}$ cycloheximide ( $\square$ ), or both of these agents ( $)$ for $8 \mathrm{~h}$. The data is expressed as the \% survival relative to untreated cells. The bars represent the standard error. Absence of error bars indicates that the error was too small to allow display of the error in those colums. Identical results were obtained by MTT assay. Cycloheximide was not cytotoxic at this concentration during the time frame of these experiments. (B) Cell survival following treatment with TNF and interferon- $\gamma$ measured by MTT assay. The HeLa transfectants described in (A) were assayed untreated $(\square)$ or following treatment with $10 \mathrm{ng} / \mathrm{ml}$ TNF ( $\square$ ), 1000 units/ml interferon- $\gamma$ ( for $8 \mathrm{~h}$. (C) Relative survival of HeLa transfectants with increasing TNF concentration. Each transfectant was treated with increasing concentrations of TNF in the presence and absence of $10 \mu \mathrm{g}$ cycloheximide, and with cycloheximide alone for $8 \mathrm{~h}$ and assayed for cell survival by crystal violet staining. The data is expressed as \% survival relative to cells treated with expression vector pRcCMV and a number of stable transfectants generated in HeLa cells. PAI-2 $265 / 87$ protein expression in the $\mathrm{CD}$ mutant clones (CDM) was monitored by immunoblot analysis as represented in Figure 1B. PAI-2 $\Delta 65 /$ 87 protein migrated with a slightly faster mobility than wildtype PAI-2 reflecting the absence of 23 amino acids or approximately $2.5 \mathrm{kD}$.

\section{Biological activity of PAI-2 $\Delta 65 / 87$}

PAI-2 $465 / 87$ was evaluated for the ability to inhibit uPA, the known serine proteinase target of PAI-2. Cell lysates derived from CDM clones containing PAI-2 $\Delta 65 / 87$ inhibited the uPA catalyzed cleavage of the synthetic substrate, Cbo-Glu-GlyArg-pNA, similar to lysates from wild-type PAI-2 as determined using the Spectrozyme UK assay (American Diagnostica, Greenwich, CT, USA) (see Materials and Methods). The ability of UPA and PAI-2 $\Delta 65 / 87$ to form a stable inhibitory complex was monitored by ${ }^{125}$-uPA binding assay. The assay is based on the formation of SDS-stable complexes between PAI-2 and ${ }^{125}$ I-labelled low molecular weight uPA tracer containing the catalytic, but not the receptor binding domain of UPA. The UPA heavy chain-PAI-2 complex appears as a $75 \mathrm{kD}$ band in cell lysates derived from both wild-type PAl-2 (S1/5) (Dickinson et al, 1995) and PAI-2 $465 /$ 87 (CDM2) cells (Figure 1C, lanes 1 and 2), but not from antisense PAI-2 (A2/7) or parental HeLa cells (Figure 1C, lanes 3 and 4). These data demonstrate that PAI- $2 \Delta 65 / 87$ is functional as an inhibitor of UPA, and show that the C-D interhelical domain is not required for the serpin inhibitory function of PAI-2.

\section{PAI-2 $265 / 87$ does not confer protection against TNF-induced apoptosis}

We have previously shown that expression of PAI-2 protects HeLa cells from apoptosis induced by TNF in the presence of the protein synthesis inhibitor cycloheximide (Dickinson et al, 1995). To investigate the importance of the C-D interhelical region in cell death, PAI-2 $\Delta 65 / 87$ transfectants were assayed for sensitivity to TNF induced apoptosis. Cell death was quantitated by two independent methods, (i) crystal violet staining, which monitors cell survival as a function of cell adherence, and (ii) MTT assay, which provides a measure of viable cells. As represented in Figure 2A, cells expressing PAI-2 $465 / 87$ (CDM7, CDM2, CDM1) were as sensitive to TNF induced apoptosis as cells which do not express PAI-2 (A2/7, CMV, parental HeLa cells), while transfectants expressing different amounts of wild-type PAI-2 showed markedly increased cell survival, ranging from $80 \%$ in the high PAI-2 expressing line (S1a) to $40 \%$ in the low expressing cell line (S1n).

Expression of wild-type PAI-2 in HeLa cells abrogates the cytostatic effect of interferon- $\gamma$ on HeLa cells as well as

cycloheximide alone. Each point represents the average of two experiments performed in triplicate. S1a $(\square)$, S1n $(O), \operatorname{CDM} 1(\diamond), \operatorname{CDM} 7(\diamond), A 2 / 7$ $(\square), \operatorname{ASM} 1(\boldsymbol{\square})$, and HeLa $(\bullet)$ 
confers resistance to apoptosis induced by the synergistic effects of TNF and interferon- $\gamma$ (Dickinson et al., 1995). As represented in Figure 2B, cells expressing PAI-2 $\Delta 65 / 87$
(CDM7, CDM2, CDM1) are not resistant to the cytostatic effect of interferon- $\gamma$ alone or the cytotoxic effects of interferon- $\gamma$ and TNF, further confirming the importance of
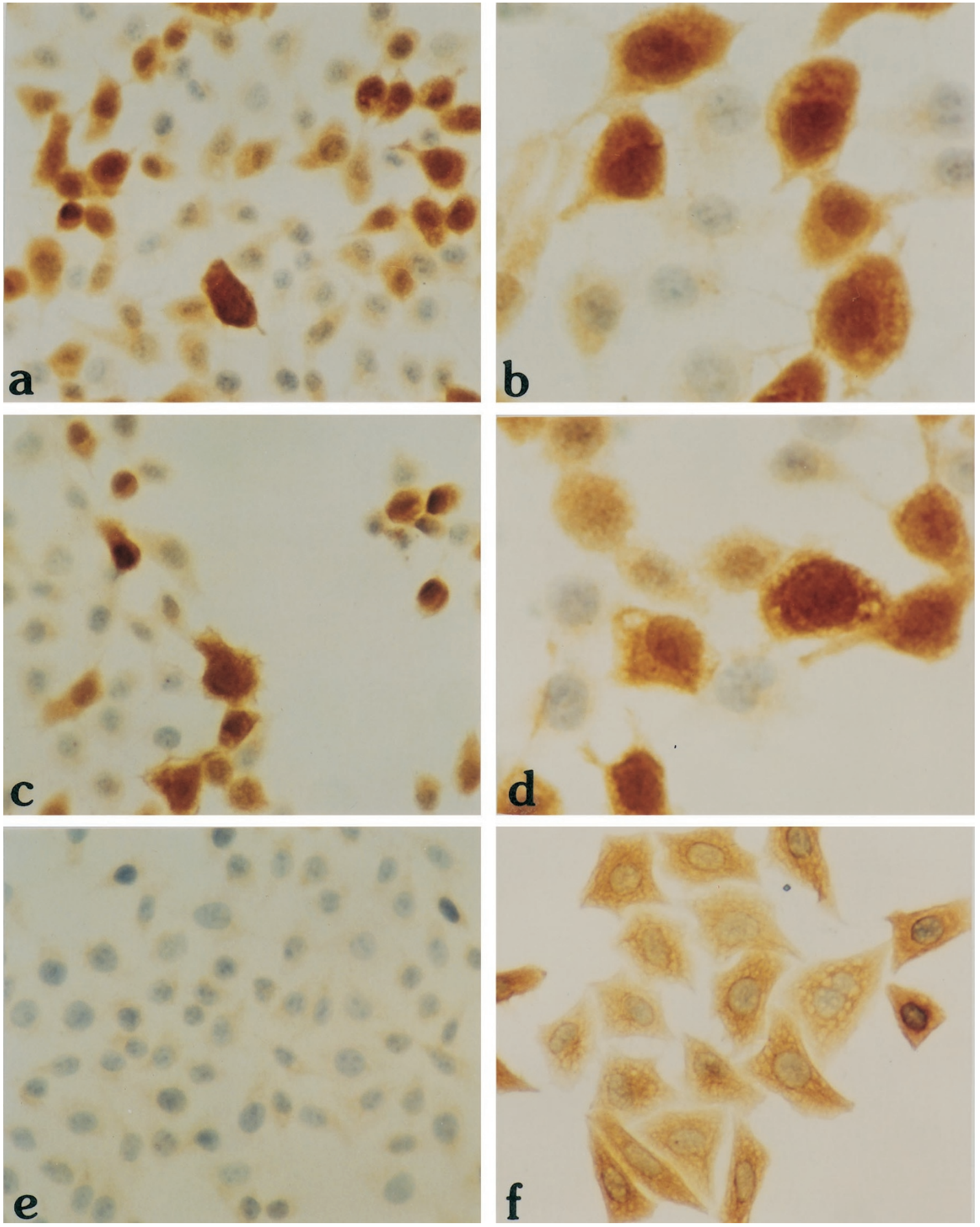

Figure 3 Immunohistochemical analysis of PAI-2 expression in untreated cells and in cells undergoing TNF-induced apoptosis. (a) PAI-2 antibody staining of untreated S1a, $250 \times$ magnification; (b) PAl-2 antibody staining of untreated S1a, $400 \times$ magnification; (c) PAI-2 antibody staining of S1a cells treated for $1 \mathrm{~h}$ with TNF and cycloheximide, $250 \times$ magnification; (d) PAl-2 antibody staining of S1a cells treated for $3 \mathrm{~h}$ with TNF and cycloheximide, $400 \times$ magnification; (e) PAl-2 antibody staining of untreated A2/7, $250 \times$ magnification; (f) cytokeratin staining of untreated $\mathrm{S} 1 \mathrm{a}, 400 \times$ magnification 
the C-D interhelical domain to PAI-2 mediated cell survival. We have previously shown that the level of protection by PAI-2 is dependent on the PAI-2 expression levels (Dickinson et al., 1995). The observed loss of protection by cells expressing PAI- $2 \Delta 65 / 87$ is unlikely due to the moderate expression levels of PAI- $2 \Delta 65 / 87$, since S1n, a wild-type PAI-2 expressing clone, which expresses less PAI-2 than each of the CDM mutants, shows protection against both TNF and interferon- $\gamma$ induced cytotoxic effects.

The sensitivity of cells expressing PAI- $2 \Delta 65 / 87$ to the dose of TNF compared with wild-type PAI-2 expressing cells is shown in Figure 2C. Wild-type PAI-2 expressing HeLa cells (S1a and S1n) demonstrate enhanced survival at concentrations of TNF ranging from $0-10 \mathrm{ng} / \mathrm{ml}$, relative to PAI-2 non-expressing cells, which show a drop in survival at $2 \mathrm{ng} / \mathrm{ml}$ that levels off at $10 \mathrm{ng} / \mathrm{ml}$. CDM1 and CDM7 are as sensitive to TNF as the PAI-2 non-expressing cells and the ASM1 cell line, which expresses an active site mutant of PAI-2 ( $\mathrm{P}_{1}$-Ala ${ }^{380}$-PAl-2) that is sensitive to TNFmediated apoptosis (Dickinson et al, 1995). Increased cell death is obtained using higher concentrations of TNF, but survival below $20 \%$ is not observed even at $100 \mathrm{ng} / \mathrm{ml} \mathrm{TNF}$, as has been reported by others (Wong et al, 1989). The reason for this is unknown but has been attributed to additional survival factors present in cells. These results demonstrate that the presence of the $C-D$ interhelical domain in the PAI-2 molecule is required for PAI-2 protection against TNF-induced apoptosis.

\section{Cellular distribution of PAl-2}

In trophoblasts and during keratinocyte differentiation, PAI-2 exhibits a pericellular distribution, which has been attributed to transglutaminase cross-linking to the plasma membrane (Lyons-Giordano et al, 1994). Given the suggested role of transglutaminase activity in the morphological changes associated with apoptosis (Jensen et al, 1995; Knight et al, 1991), we investigated whether PAl-2 may be associated with cellular structures in PAI-2 expressing cells and/or whether the apoptotic stimuli may induce changes in PAI-2 cellular distribution. Immunohistochemical analyses were performed to investigate the distribution of PAI-2 in S1a cells and PAI-2 localization during induction of apoptosis. As shown in Figure $3 a$ and $b$, intense diffuse cytoplasmic staining of PAI-2 is observed in untreated S1a cells with no apparent accentuation of the cell membrane. This is in contrast to the distinct pattern of cytokeratin staining (Figure 3f) and the periplasmic staining of PAl-2 in human keratinocytes (Jensen et al, 1995). No staining was detected in the absence of antibody (data not shown) or in the non-PAI-2 expressing A2/7 cells (Figure 3e). Immuno-detection of PAI-2 was dependent on permeabilization of the S1a cells (data not shown), indicating the absence of PAI-2 on the cell surface. Treatment with TNF and cycloheximide to induce apoptosis for $1 \mathrm{~h}$ (Figure 3c) had no discernible effect on the PAI-2 cytoplasmic staining pattern. Following treatment with TNF and cycloheximide for $3 \mathrm{~h}$, when A2/7 cells show distinct morphological changes associated with apoptosis (Dickinson et al, 1995; data not shown), the diffuse cytoplasmic distribution of PAI-2 is not changed (Figure 3d). These results show that PAI-2 does not distribute pericellularly, in response to apoptotic stimuli in these cells.

Immunofluorescent staining of PAI-2 $\Delta 65 / 87$ in CDM1 cells showed a diffuse, cytoplasmic staining pattern (Figure
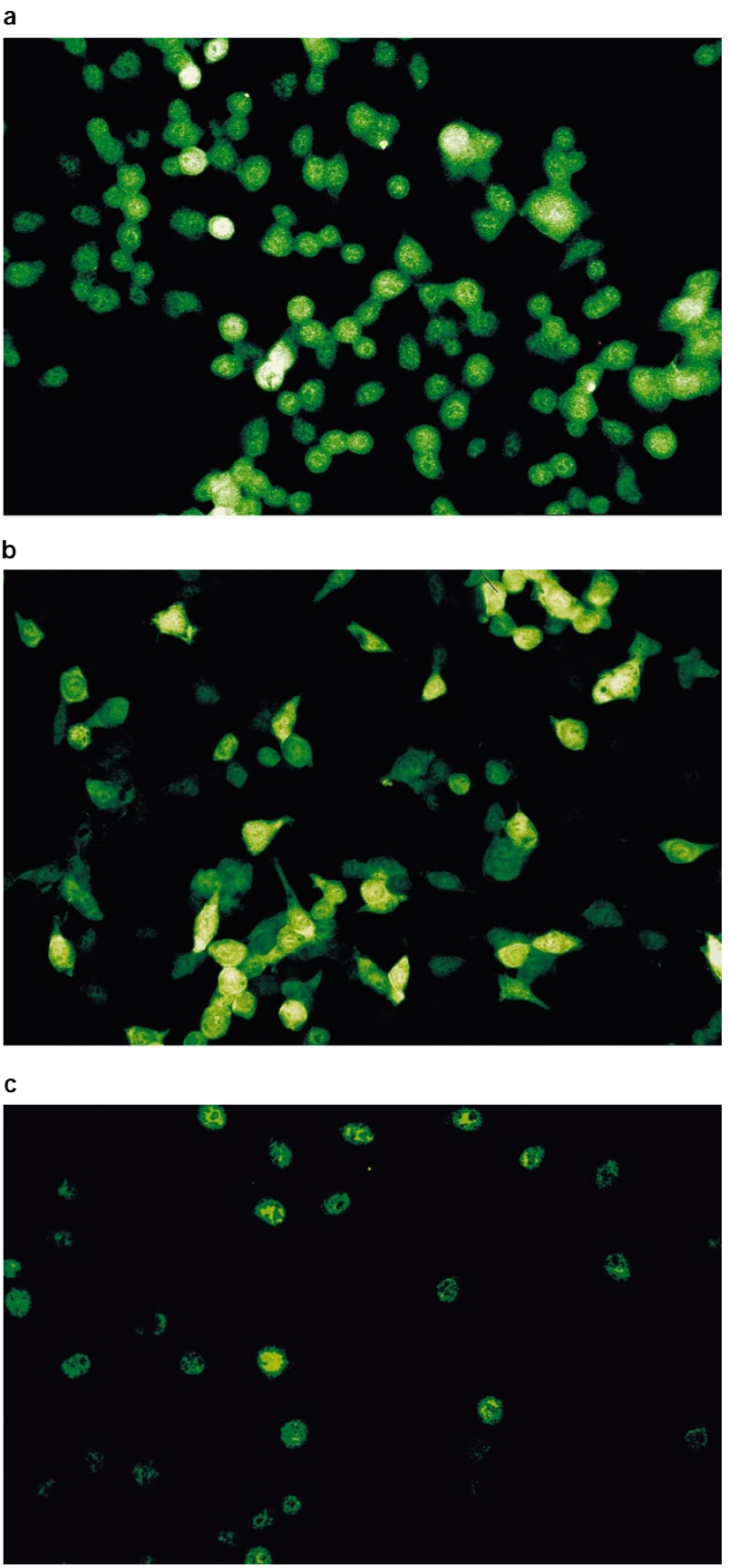

Figure 4 Localisation of PAI-2 $\Delta 65 / 87$ by immunofluorescence. PAI-2 polyclonal antibody staining of PAI-2 $265 / 87$ in untreated CDM1 cells (a), wild-type PAl-2 expressing untreated S1a cells (b), and anti-sense PAI-2 expressing untreated A2/7 cells (c) $(100 \times$ magnification). The stronger staining of S1a cells reflects the higher amount of PAl-2 species expressed in these cells relative to CDM1 cells. Staining of PAI-2 non-expressing A2/7 cells shows the level of nonspecific background staining associated with the primary polyclonal antibody, as no staining was detected in the absence of antibody 
4a) similar to that observed for wild-type PAI-2 (Figure 4b), although the intensity of staining was less, likely due to the lower level of PAI-2 species expressed by these cells. Treatment with TNF and cycloheximide for $2 \mathrm{~h}$ had no apparent effect on the localisation of PAI-2 $\Delta 65 / 87$ (data not shown).

Subcellular fractionation studies were performed with both untreated S1a cells and S1a cells treated with the TNF and cycloheximide death signal to further establish the subcellular location of PAI-2. Expression of PAI-2 in each subcellular fraction was monitored by immunoblot analysis. PAI-2 was associated with the soluble cytosolic fraction, in both untreated and TNF and cycloheximide treated cells (Figure 5, Lane 4), while no PAI-2 could be detected in the membranous fractions. A minimal amount of PAI-2 was associated with both the soluble and insoluble nuclear fractions (Figure 5, Lanes 6 and 7) both in the presence and absence of TNF and cycloheximide. The amount of PAI-2 associated with the nuclear fractions was very low to negligible and highly variable, suggesting that it is nonspecific and/or a result of minor whole cell contamination of the isolated nuclei. Thus, the apparent staining of some nuclei in Figure 3 is probably nonspecific, possibly resulting from procedures used in cell fixation. No evidence for secretion of PAI-2 could be detected in culture supernatants of in vivo labelled S1a cells either in the presence or absence of TNF and cycloheximide (data not shown).

\section{Discussion}

In this study we demonstrate that a second domain found between the $\mathrm{C}$ and $\mathrm{D} \alpha$-helices of PAI- 2 is functionally important for protection of PAI-2 from TNF $\alpha$ induced apoptosis. Mutants of PAI-2 lacking the C-D interhelical domain, while retaining functional proteinase inhibitory activity against UPA, failed to protect from apoptosis induced by TNF and were not resistant to interferon- $\gamma$ induced cytostasis. Further, PAI-2 protection against TNF induced apoptosis was demonstrated to be due to intracellular PAI-2, and was not associated with cross-linking of PAl-2 to the plasma membrane.

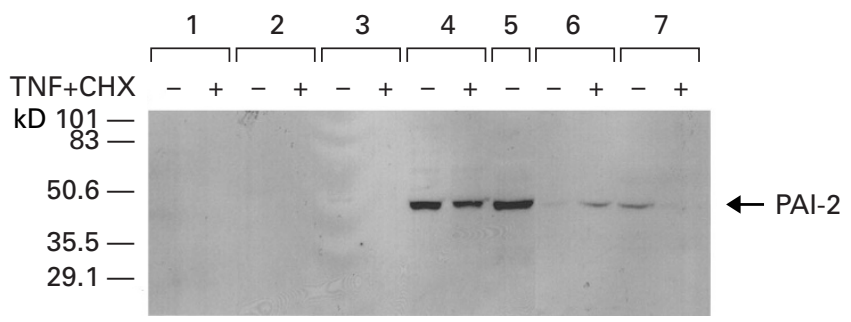

Figure 5 Subcellular distribution of PAI-2 in untreated cells and in cells undergoing TNF-induced apoptosis. S1a cells, either untreated $(-)$ or treated with TNF and cycloheximide (+) for $4 \mathrm{~h}$ were fractionated as described in the Materials and Methods. Lane 1, heavy mitochondrial fraction (PI); Lane 2, light mitochondrial fraction (P2); Lane 3, microsomal fraction (P3); Lane 4, soluble cytosolic fraction; Lane 5 , untreated whole cell S1a lysate; Lane 6 , insoluble nuclear fraction; Lane 7 , soluble nuclear fraction
Transglutaminase-catalyzed crosslinking to $\mathrm{Gln}^{83}, \mathrm{Gln}^{84}$, and $\mathrm{Gln}^{86}$ within the C-D interhelical region of PAI-2 in vitro has been reported (Jensen et al, 1994; Jensen et al, 1993) and this has been postulated to contribute to the observed pericellular distribution of PAI-2 in terminally differentiated keratinocytes (Lyons-Giordano et al, 1991; Jensen et al, 1995). Transglutaminases are a family of calcium dependent enzymes that catalyse the cross-linking of cellular constituents resulting in stabilization of structures such as keratinocyte cornified envelopes and fibrin clots (Knight et al, 1991). Increased transglutaminase activity is associated with apoptosis where cross-linking of many cellular components occurs, forming the apoptotic envelope (Knight et al, 1991; Fesus et al, 1996; Gentile et al, 1992). Given the role of transglutaminases in apoptosis and the in vitro evidence linking PAI-2 and transglutaminase-catalyzed crosslinking through the C-D interhelical domain, it was hypothesized that crosslinking of PAI-2 to cellular membranes may be important for PAI-2 protection from apoptosis. The immunostaining and subcellular fractionation data show that treatment of PAI-2 expressing cells with TNF and cycloheximide under conditions that induce apoptosis in control cells, does not demonstrably change the diffuse cytoplasmic distribution of PAI-2, and no evidence from fractionation studies could be found to implicate attachment of PAI-2 to cell membranes during the apoptotic process. Thus it appears that pericellular distribution of PAl-2 is not a requirement for, or an indicator of, the protective function of PAI-2 from apoptosis in these cells.

While the C-D interhelical region does not appear to be involved in the crosslinking of PAI-2 during the apoptotic process, its presence was clearly important for PAI-2 protection. This may suggest that the $C-D$ interhelical region is important for the maintenance of other functional domains within the PAI-2 molecule or more likely, that specific amino acids within the C-D interhelical region itself are involved in the protective mechanism. Comparison of the primary sequence of PAI-2 with the sequences and crystal structures of other serpins indicates that the C-D interhelical region is positioned at the opposite end of the molecule to the RSI. The high structural conservation amongst serpins and the maintenance of UPA binding activity in the C-D deletion mutants argue strongly for the deletion having a minimal effect on the integrity of the RSL domain.

Comparison of the species conservation among the amino acids contained within the C-D interhelical region of PAI-2 reveals several candidates that may be critical for its biological function (highlighted by asterisks in Figure 1A). The amino acids $\mathrm{Cys}^{79}, \mathrm{Gln}^{83}, \quad 1 \mathrm{e}^{85}$ and $\mathrm{Gln}^{86}$ are conserved among all three species. Cys ${ }^{79}$ may play a role in intermolecular or intramolecular interactions involving disulfide cross-linking of PAI-2 (Wun et al, 1987; Radke et al, 1990). The region spanning amino acids 7376 and containing the motif PENFT is also conserved and may have functional significance. Mutagenesis studies targeting specific amino acid motifs will be required to localize those amino acids critical for the PAI-2 protective mechanism.

Interaction of the C-D interhelical domain and other proteins is likely to be important for resistance to apoptosis. 
Recent studies demonstrate that the C-D interhelical region may participate in reversable interactions with cytosolic proteins (Jensen et al, 1996) Annexins I, II, IV and V have been demonstrated to bind the C-D interhelical region of $\mathrm{PAl}-2$ in vitro in a calcium independent manner (Jensen et al, 1996). The annexins are a family of $\mathrm{Ca}^{2+}$ and membrane phospholipid binding proteins that participate in membranerelated translocation, exocytosis and signalling events. The process of apoptosis leads to characteristic morphological changes in the plasma membrane and cytoplasm which may well involve annexins. While the role of annexins in apoptosis is only beginning to be elucidated, members of this family bind to phosphatidylserine, whose externalization is a marker of apoptosis (Vermes et al, 1995), and are involved in the regulation of phospholipase $\mathrm{A}_{2}$ activity during apoptosis in thymocytes (Sakamoto et al, 1996). It is possible that binding of annexins to the C-D interhelical domain of PAI-2 could play a role in conferring resistance to apoptosis. As well as the annexins, as yet unidentified proteins of 100,70 and $50 \mathrm{kDa}$ co-precipitate with PAI-2 following immunoprecipitation of dithiobis(succinimidylproprionate)-crosslinkined proteins. It is interesting to speculate that one or more of these proteins may be involved in the protective action of PAI-2. If this were the case, PAI-2 would not be unique among serpins in possessing a secondary functional domain involved in intermolecular interactions, in addition to the RSL domain recognised by its cognate serine proteinase(s). PAl-1, an inhibitor of plasminogen activators, is synthesized in a conformationally latent form which becomes activated following binding to vitronectin through a domain between $C$ and $E$ helices which is distinct from its RSL domain (Lawrence et al, 1994). The inactivation of target enzymes by several serpins that regulate blood clotting in plasma, such as antithrombin III and heparin cofactor II, is greatly accelerated by binding to glycosaminoglycans through heparin binding domains located in the respective Dhelices (Church et al, 1992). The C-D interhelical domain in PAI-2 may play a similar role in regulating PAI-2 mediated inhibition of proteolytic activity within the cell during apoptosis. Interactions with this domain may regulate, or potentially activate, $\mathrm{PAI}-2$ inhibitory activity towards an intracellular proteinase target and/or may participate in intra-molecular protein interactions. The function of this PAI-2 domain clearly requires further study to elucidate these possibilities.

\section{Materials and Methods}

\section{Cells and cell culture}

HeLa S3 cells were obtained from the American Type Culture Collection (ATCC CLL 2). HeLa cell lines stably transfected with wildtype PAI-2 cDNA (S1a, S1/5, S1n), P -Ala $^{380}$-PAI-2 (ASM1), antisense PAI-2 CDNA (A2/7), and vector alone (CMV) under the control of the cytomegalovirus promoter (pRcCMV) were generated as described (Dickinson et al, 1995). Cell lines were incubated in $5 \% \mathrm{CO}_{2}$ and $95 \%$ air atmosphere at $37^{\circ} \mathrm{C}$ and cultured in RPMI 1640 medium supplemented with $10 \%$ fetal calf serum, $2 \mathrm{mM}$ glutamate, $25 \mathrm{mM}$ HEPES buffer, $60 \mathrm{mg} / \mathrm{ml}$ penicillin G (CSL, Melbourne, Australia) and $100 \mathrm{mg} / \mathrm{ml}$ streptomycin sulfate (CSL). Transfected lines were maintained in $300 \mu \mathrm{g} / \mathrm{ml}$ G418 (Gibco-BRL, Melbourne, Australia). Cell viability was determined by trypan blue dye exclusion. All cultures were checked routinely and determined to be mycoplasma free.

\section{cDNA constructs}

The C-D interhelical mutant of PAI-2 was engineered using a PCRbased loop-out mutagenesis procedure allowing deletion of $69 \mathrm{bp}$ spanning nt 267-336 of PAl-2 cDNA. A 317 bp Pstl/Pvull fragment, extending from the Pstl restriction enzyme site in the pUC8 polylinker of pJ7/PAl-2 (Schleuning et al, 1987) to the Pvull restriction enzyme site within PAI-2 was excised from J7/PAl-2. Using the $317 \mathrm{bp}$ fragment as the template, a $326 \mathrm{bp}$ DNA fragment extending from Hindlll in the pUC8 polylinker of J7/PAI-2 to the Pstl site within the PAI-2 cDNA was generated by PCR amplification using primers $E$ and $F$, listed below, Primer E spans the pUC8 polylinker in J7/PAI-2 from the Hindlll restriction enzyme site and includes an inserted Notl site. Primer $\mathrm{F}$ spans bases $249-266$ fused to $337-376$ of PAI-2 CDNA, thus incorporating the deletion of $69 \mathrm{bp}$.

Primer E: 5'-ACGCCAAGCTTGGCGGCCGCTCGACGGATCCCCGGGAATTC-3'

Primer F: 5'-TTTATCTGCAGCTTGTGCCTGCAAAATCGCATCAGGATAACTACCTCCCACTTCATTAAACTG-3'

The generated 326 bp DNA fragment was digested with Hindll and $P s t l$ and cloned into J7/PAI-2 following excision of the wild-type PAI-2 Hindll//Pstl fragment to generate J7/PAI-2 $\Delta C D$. The 1811 bp full length PAI-2 $\triangle C D$ cDNA was excised from J7/PAl-2 $\triangle C D$ by EcoRI digestion, end-filled and cloned into Hindlll digested, blunt-ended pRc/ CMV generating PAI-2 $\Delta 65 / 87$ (Figure $1 \mathrm{~A}$ ). The correct orientation and sequence was verified by DNA sequencing.

\section{Transfection and selection of stable PAI-2 CD mutant clones in HeLa cells}

Approximately $1 \times 10^{7}$ cells in log phase were electroporated with $20 \mu \mathrm{g}$ plasmid DNA at 0.25 volts, $960 \mu \mathrm{FD}$ in RPMl 1640 containing $10 \%$ fetal calf serum. Following culture for $16 \mathrm{~h}$, transfectants were selected with $0.8 \mathrm{mg} / \mathrm{ml} \mathrm{G418} \mathrm{(Gibco-BRL,} \mathrm{Melbourne,} \mathrm{Australia)}$ essentially as described (Dickinson et al, 1995). Expression of the transgene in isolated clones was monitored by Northern and immunoblot analyses as described (Dickinson et al, 1995). Antibodies used were an anti-PAI-2 monoclonal antibody (\#3750, American Diagnostica, Greenwich, CT, USA) or goat anti-PAI-2 polyclonal antibody (Biotech Australia, Pty. Ltd., Sydney, Australia). Protein concentration was determined by Bio-Rad Protein assay.

\section{UPA inhibitory activity}

uPA inhibitory activity was determined by standard chromogenic assay (Spectrozyme UK, American Diagnostica). Crude protein extracts from cell lines expressing wild-type PAI-2 (S1a) and PAI-2 $\Delta 65 / 87$ (CDM1) had a similar range of inhibitory activity against uPA (80-100 inhibitory units $/ \mathrm{mg}$ ) when the data was corrected for the amount of PAl-2 present in the extracts estimated by Western blot analysis.

\section{uPA binding activity}

Low molecular weight (LMW)-uPA (33 kD) was labelled with ${ }^{125}$ I to a specific activity of $40 \mathrm{mCi} / \mathrm{mg}$ as previously described (Jensen et al, 
1990). Cells were rinsed in ice cold PBS prior to lysis on ice in (120 mM NaCl, 50 mM HEPES, pH 7.4, 5 mM EDTA, 3 mM EGTA, $0.05 \mathrm{mg} / \mathrm{ml}$ aprotinin, $1 \mathrm{mg} / \mathrm{ml} \mathrm{SBTI}, 2 \mathrm{mM}$ PMSF, $2 \mathrm{mM}$ iodoacetamide, $0.25 \mathrm{M}$ sucrose, $1 \%$ Triton $\mathrm{X} 100$ ) at a concentration of $4 \times 10^{6}$ / $\mathrm{ml}$ (Jensen et al, 1994). The extract was cleared by centrifugation for $15 \mathrm{~min}$ at $4^{\circ} \mathrm{C}$ at $15000 \mathrm{~g} .15 \mu$ of the supernatant was incubated with approximately 50000 c.p.m. ${ }^{125}$ I-LMW-uPA for $60 \mathrm{~min}$. The incubation was terminated by adding $15 \mu \mathrm{l} 2 \times$ SDS-loading buffer, heating to $95^{\circ} \mathrm{C}$ for $5 \mathrm{~min}$ followed by analysis on $8-16 \%$ gradient SDS-PAGE. The gels were stained, dried and subjected to autoradiography overnight at $-80^{\circ} \mathrm{C}$ using Hyperfilm MP (Amersham International, Buckinghamshire, UK). Prestained molecular weight markers were from Novex, USA.

\section{TNF cytolysis assays}

Cells were seeded at $10^{4}$ cells per well in triplicate in 96-well plates for $16 \mathrm{~h}$ prior to the treatments described in the Figure Legends. For assay by crystal violet staining, the cells were washed in PBS and stained with $0.2 \%$ crystal violet in $10 \%$ ethanol or $10 \%$ formaldehyde. The dye was eluted with $33 \%$ acetic acid and the absorbance was measured at $480 \mathrm{~nm}$. For measurement by MTT assay, 3-(4,5dimethylthiazol-2-yl)-2,5-diphenyl tetrazolium bromide (MTT, SigmaAldrich) was added to a final concentration of $0.4 \mathrm{mg} / \mathrm{ml}$ per well and incubated for $4 \mathrm{~h}$. Plates were centrifuged at $800 \times g$ for $5 \mathrm{~min}$ and supernatant removed. MTT crystals were dissolved in DMSO and the absorbance was measured at $570 \mathrm{~nm}$.

\section{Immunohistochemistry}

S1a and A2/7 cells were seeded in sterile 8-well chamber slides (Nunc, Australia) and allowed to adhere overnight to replacing the supernatant with control media or media containing $10 \mathrm{ng} / \mathrm{ml}$ TNF and $10 \mu \mathrm{g} / \mathrm{ml} \mathrm{CHX}$. After incubation for $1 \mathrm{~h}$ or $3 \mathrm{~h}$, the cells were washed and fixed in 100\% cold methanol for 2 min. Slides were then rinsed in PBS, and endogenous peroxidase activity was inhibited with $0.3 \%$ $\mathrm{H}_{2} \mathrm{O}_{2}$ and $0.1 \%$ sodium azide, and non-specific antibody binding was inhibited by immersion in $4 \%$ non-fat skim milk powder. Endogenous biotin activity was blocked with $0.1 \%$ avidin (Dakopatts, Carpinteria, CA) followed by $0.01 \%$ D-biotin. Non-specific antibody binding was further inhibited by pre-incubating the slides with $10 \%$ non-immune goat serum. Cells were incubated with primary antibody (anti PAI-2 monoclonal antibody, American Diagnostica), or no antibody, for $30 \mathrm{~min}$ at room temperature, then biotinylated goat anti-mouse immunoglobulins (Zymed, San Francisco, CA) followed by streptavidin-horseradish peroxidase complex (Zymed, San Francisco, CA). Antigenic sites were demonstrated using $3,3^{\prime}$-diaminobenzidine as chromogen with $\mathrm{H}_{2} \mathrm{O}_{2}$ as substrate. Cells were counterstained with Harris' haematoxylin and mounted in Permount.

\section{Immunofluorescence}

S1a, A2/7 and CDM1 cells were seeded in sterile 8-well chamber slides (Nunc, Australia) and allowed to adhere overnight prior to replacing the supernatant with control media or media containing $10 \mathrm{ng} / \mathrm{ml} \mathrm{TNF}$ and $10 \mu \mathrm{g} / \mathrm{ml} \mathrm{CHX}$. After incubation for $2 \mathrm{~h}$, the cells were washed and fixed in $100 \%$ cold methanol for 2 min and allowed to dry. Slides were then rinsed in PBS, blocked with PBS containing $4 \%$ nonfat milk powder, and then with PBS containing $0.3 \%$ Triton X100. Non-specific antibody binding was further inhibited by pre-incubating the slides with $10 \%$ non-immune fetal calf serum. Cells were incubated with primary antibody (polyclonal anti-PAI-2 antibody, Biotech
Australia Pty. Ltd., Sydney, Australia), or no antibody, overnight at $4{ }^{\circ} \mathrm{C}$. After several washing and blocking steps, as above, antigenic sites were visualized with FITC-labelled sheep anti-goat antibody (Silenuis, Melbourne, Australia).

\section{Subcellular distribution of PAI-2}

Subcellular fractionation was adapted from Yuan et al. (1996). Subconfluent S1a cells $\left(2 \times 10^{7}\right)$ were incubated with control media or media containing $10 \mathrm{ng} / \mathrm{ml}$ TNF and $10 \mu \mathrm{g} / \mathrm{ml} \mathrm{CHX} \mathrm{for} 4 \mathrm{~h}$. The cells were harvested by gentle scraping and after $3 \times$ PBS washes, were resuspended in $100 \mu \mathrm{l}$ chilled hypotonic buffer (10 mM HEPES, $\mathrm{pH} 7.9,1.5 \mathrm{mM} \mathrm{MgCl}_{2}, 10 \mathrm{mM} \mathrm{KCl}, 0.1 \mathrm{mM}$ EDTA, $1 \mathrm{mM}$ DTT, $0.25 \mathrm{M}$ sucrose, and $1 \mathrm{mM}$ of the serine proteinase inhibitor, AEBSF). Suspensions were incubated for $30 \mathrm{~min}$ on ice and subjected to 20-25 strokes of Dounce homogenisation. The nuclei were then pelleted by centrifugation at $1000 \mathrm{~g}$ for $6 \mathrm{~min}$ at $4^{\circ} \mathrm{C}$. The cytoplasmic fraction was subjected to sequential centrifugation at $4{ }^{\circ} \mathrm{C}$ as follows: $300 \mathrm{~g}$ for $10 \mathrm{~min}$ to pellet the heavy mitochondrial fraction (P1), $17000 \mathrm{~g}$ for $10 \mathrm{~min}$ to pellet the light mitochrondrial fraction (P2), and $100000 \mathrm{~g}$ for $45 \mathrm{~min}$ to pellet the microsomal fraction (P3). The P2 fraction contains mitochondria, lysosomes, peroxisomes, Golgi membranes and some endoplasmic reticulum. The P1 fraction contains predominantly mitochondria, but may also contain minor components from the P2 fraction entrapped during pelleting. The P3 fraction contains membrane vesicles, e.g. endosomes, trans-Golgi vesicles and disrupted plasma membrane. The final supernatant was the soluble cytosolic fraction. The nuclei pelleted in the first centrifugation were resuspended in $0.5 \mathrm{ml}$ of hypotonic buffer without sucrose and washed through a $0.25 \mathrm{M}$ sucrose cushion $(0.5 \mathrm{ml})$ at $1600 \mathrm{~g}$ for $5 \mathrm{~min}$. Purification through the sucrose cushion removes cell debris from the nuclear preparations, but does not remove possible minor contamination with whole, unbroken cells. The nuclei were lysed in hypotonic buffer containing $0.5 \%$ Triton $\mathrm{X} 100$ at $4{ }^{\circ} \mathrm{C}$ for $30 \mathrm{~min}$ and centrifuged at $14000 \mathrm{~g}$ for $10 \mathrm{~min}$ to pellet the insoluble nuclear fraction. The supernatant portion presents the Triton-soluble nuclear fraction. Aliquots of each fraction representing the same cellular volume were analyzed on $10 \%$ SDS - PAGE reducing gels and immunoblotted as above.

\section{Acknowledgements}

We thank Michael Walsh from the Department of Surgery, University of Queensland, for assistance with the immunohistochemistry and the photographs. We also thank Julie Muddiman and Kathy Buttigieg for assistance with experiments contributing to this work and for helpful discussions. We thank Biotech Australia, Pty. Ltd., Sydney, Australia, for supplying goat anti-PAl-2 antibodies. This work was supported by the Queensland Cancer Fund and the National Health and Medical Research Council of Australia. JLD was supported in part by the Dora Lush PostGraduate Biomedical Scholarship from the National Health and Medical Research Council of Australia. PHJ was funded by the Danish Cancer Society (78-2000), Fru Astrid Thaysens Legat, Grosserer Valdemar Foersom og Hustru Thyra Foersoms Fond, Lily Benthine Lunds Fond, Direktor Leo Nielsen og Hustru Karen Margrethe Nielsens Legat.

\section{References}

Antalis TM, Clark MA, Barnes T, Lehrbach PR, Devine PL, Schevzov G, Goss NH Stephens RW and Tolstoshev P (1988) Cloning and expression of a cDNA coding for a human monocyte derived plasminogen activator inhibitor. Proc. Natl. Acad. Sci. U.S.A. 85: $985-989$ 
Antalis TM and Dickinson JL (1992) Control of plasminogen-activator inhibitor type gene expression in the differentiation of monocytic cells. Eur. J. Biochem. 205 203-209

Chomcyznski P and Sacchi N (1987) Single-step method of RNA isolation by acid guanidinium thiocyanade-phenol-chloroform extraction. Anal. Biochem. 162: $156-159$

Church FC, Pratt CW and Whinna HC (1992) A comparison of three heparin-binding serine proteinase inhibitors. J. Biol. Chem. 267: 8795-8801

Dickinson JL, Bates EJ, Ferrante A and Antalis TM (1995) Plasminogen activator inhibitor-type 2 inhibits TNF $\alpha$-induced apoptosis: Evidence for an alternate biological function. J. Biol. Chem. 270: 27894-27904

Feinberg AP and Vogelstein B (1983) A technique for radiolabelling DNA restriction endonuclease fragments to high specific activity. Anal. Biochem. 132: 6-13

Fesus L, Madi A, Balaithy Z, Nemes Z, Szondy Z (1996) Transglutaminase induction by various cell death and apoptosis pathways. Experientia 52(10-11): $942-949$

Gan H, Newman GW and Remold HG (1995) Plasminogen activator inhibitor type 2 prevents programmed cell death of human macrophages infected with mycobacterium avium Serovar 4. J. of Immunol. 155: 1304-1315

Gentile V, Thomazy V, Piacentini M, Fesus L and Davies PJA (1992) Expression of tissue transglutaminase in Balb-C 3T3 fibroblasts: effects on cellular morphology and adhesion. J. Cell. Biol. 119: 463-474

Jensen PH, Christensen El, Ebbesen P, Gliemann J and Andreasen PA (1990) Lysosomal degradation of receptor-bound urokinase-type plasminogen activator is enhanced by its inhibitors in human trophoblastic chroiocarcinoma cells. Cell Reg. 1: 1043-1056

Jensen PH, Cressey LI, Gjertsen BT, Madsen P, Melgren G, Hokland P, Gliemann J Døskeland SO, Lanotte M and Vintermyr OK (1994) Cleaved intracellular plasminogen activator inhibitor 2 in human myeloleukaemia cells is a marker of apoptosis. Brit. J. Cancer. 70: 834-840

Jensen PH, Jensen TG, Laug WE, Hager H, Gliemann J and Pepinsky B (1996) The exon 3 encoded sequence of the intracellular serine proteinase inhibito Plasminogen activator inhibitor-2 (PAl-2) is a protein binding domain. J. Biol. Chem. 271: 26892-26899

Jensen PH, Lorand L, Ebbesen P and Gliemann J (1993) Type-2 plasminogenactivator inhibitor is a substrate for trophoblast transglutaminase and Factor XIIla. Eur. J. Biochem. 214: 141-146

Jensen PH, Schuler E, Woodrow G, Richardson M, Goss N, Hojrup P, Peterson TE and Rasmussen LK (1994) A unique interhelical insertion in plasminogen activator inhibitor-2 contains three glutamines $\mathrm{Gln}^{83} \mathrm{Gln}^{84} \mathrm{Gln}^{86}$ essential for transglutaminase-mediated cross-linking. J. Biol. Chem. 269: 15394-15398

Jensen PJ, Wu Q, Janowitz P, Ando Y and Schechter NM (1995) Plasminogen activator inhibitor type 2: an intracellular keratinocyte differentiation product that is incorporated into the cornified envelope. Exp. Cell Res. 217: 65-71

Kiso U, Kaudewitz H, Henschen A, Astedt B, Kruithof EKO and Bachmann F (1988) Determination of intermediates products and cleavage site in the reaction between plasminogen activator inhibitor type-2 and urokinases. FEBS Letts. 230: $51-56$

Knight CR, Rees RC and Griffin M (1991) Apoptosis: a potential role for cytosolic transglutaminase and its importance in tumour progression. Biochem. Biophys. Acta. 1096: 312-318

Kruithof EKO, Baker M and Bunn CL (1995) Biological and clinical aspects of plasminogen activator inhibitor type 2. Blood 86: 4007-4024

Kumar S and Baglioni C (1991) Protection from tumor necrosis factor-mediated cytolysis by overexpression of plasminogen activator inhibitor type 2. J. Biol. Chem. 266: 20960-20964
Lawrence DA, Berkenpas MB, Palaniappan S and Ginsburg D (1994) Localization of vitronectin binding domain in plasminogen activator inhibitor-1. J. Biol. Chem. 269: $15223-15228$

Loebermann H, Tokuoka R, Deisenhofer J and Huber R (1984) Human $\alpha 1$-proteinase inhibitor: Crystal structure analysis of two crystal modifications molecular model and preliminary analysis of the implications for function. J. Mol. Biol. 177: 531 556

Lyons-Giordano B, Loskutoff D, Chen CS, Lazarus G, Keeton M and Jensen PJ (1994) Expression of plasminogen activator inhibitor type 2 in normal and psoriatic epidermis. Histochem. J. 101: 105-112

Radtke KP, Wenz KH and Heimburger N (1990) Isolation of plasminogen activator inhibitor-2 (PAl-2) from human placenta. Evidence for vitronectin/PAI-2 complexes in human placenta extract. Biol. Chem. Hoppe-Seyler 371: 11191127

Remold-O'Donnell E (1993) The ovalbumin family of serpin proteins. FEBS Letters 315 (2): $105-108$

Sakamoto T, Repasky WT, Uchida K, Hirata A and Hirata F (1996) Modulation of cell death pathways to apoptosis and necrosis of $\mathrm{H}_{2} \mathrm{O}_{2}$-treated rat thymocytes by lipocortin I. Biochem. Biophys. Res. Comm. 220: 643-647

Samia JA, Alexander SJ, Horton KW, Auron PE, Byers MG, Shows TB and Webb AC (1990) Chromosomal organization and localization of the human urokinase inhibitor gene: Perfect structural conservation with ovalbumin. Genomics 6 : $159-167$

Schleuning W-D, Medcalf RL, Hession C, Rothenbuhler R, Shaw A and Kruithof EKO (1987) Plasminogen activator inhibitor 2: regulation of gene transcription during phorbol ester-mediated differentiation of U-937 human histiocytic lymphoma cells. Mol. Cell. Biol. 7: 4564-4567

Testa JE and Quigley JP (1990) The role of urokinase-type plasminogen activator in aggressive tumor cell behavior. Canc. Metast. Rev. 9: 353-367

Vermes I, Haanen C, Steffensnakken H and Reutelingsperger C (1995) A nove assay for apoptosis. Flow cytometric detection of phosphatidylserine expression on early apoptotic cells using fluorescein labelled Annexin V. J. Immunol. Methods. 184: $39-51$

Wong GHW, Elwell JH, Oberley L and Goeddel DV (1989) Manganous superoxide dismutase is essential for cellular resistance to cytotoxicity to tumor necrosis factor. Cell 58: 923-931

Wun T-C and Reich E (1987) An inhibitor of plasminogen activation from human placenta. Purification and characterization. J. Biol. Chem. 262: 3636-3653

Ye RD, Ahern SM, Le Beau MM, Lebo RV and Sadler JE (1989) Structure of the gene for human plasminogen activator inhibitor-2. The nearest mammalian homologue of chicken ovalbumin. J. Biol. Chem. 264: 5495-5502

Ye RD, Wun TC and Sadler JE (1987) cDNA cloning and expression in Eschericha coli of a plasminogen activator inhibitor from human placenta. J. Biol. Chem. 262 $3718-3725$

Yuan Z-M, Huang Y, Kraeft S-K, Chen LB, Kharbanda S and Kufe D (1996) Interaction of cyclin-dependent kinase 2 and the Lyn tyrosine kinase in cells treated with 1 beta-D-arabinofuranosylcytosine. Oncogene 13: 939-946

Zhou Q, Snipas S, Orth K, Muzio M, Dixit VM and Salvensen GS (1997) Target protease specificity of the viral serpin CrmA. Analysis of five caspases. J. Biol. Chem. 272: $7797-7800$ 